\title{
Acceptance of illness and need for education to support dermatology self-care in psoriasis patients: a cross-sectional study
}

\author{
Moetaza M. Soliman \\ Department of Pharmacy Practice, Faculty of Pharmacy, Mansoura University, Mansoura, Egypt \\ Adv Dermatol Allergol 2021; XXXVIII (5): 842-849 \\ DOI: https://doi.org/10.5114/ada.2020.95655
}

\begin{abstract}
Introduction: Acceptance of illness greatly affects the quality of life of psoriatic patients. Assessment of patients' need for education and support is very important for patients' counselling and follow-up.

Aim: To evaluate acceptance of illness and need for education to support dermatology self-care in Arabic patients with psoriasis.

Material and methods: A cross-sectional study using a survey was conducted. The survey collected patients' demographics, disease characteristics, Acceptance of Illness Scale (AIS) and Person-Centered Dermatology Self-Care Index (PeDeSI). Outcome measures were presented in total and in relation to age, gender, disease duration, disease severity, quality of life and level of education. The correlation between AIS and PeDeSI was examined using Spearman's rank correlation test.

Results: In total, 209 psoriatic patients from 12 Arabic countries participated in the survey with mean \pm SD age of $35.8 \pm 10.0$ years. The median (IQR) AIS score was 28 (19-35). The median (IQR) of the PeDeSI score was 15 (11-22). Both AIS and PeDeSI did not differ in relation to age, gender, disease duration, and level of education. However, patients with a higher impairment in quality of life reported lower levels of illness acceptance $(p=0.001)$ and a higher need for education and support $(p=0.004)$. AIS and PeDeSI were moderately correlated ( $r h o=0.33, p<0.001$ ).

Conclusions: Arabic psoriatic patients showed moderate acceptance of illness and required some education to support dermatology self-care. Greater clinical attention with focus on patient education and counselling should be given to Arabic patients with psoriasis especially those with more impaired quality of life.
\end{abstract}

Key words: psoriasis, acceptance of illness, dermatology self-care, cross-sectional.

\section{Introduction}

Psoriasis is an immune-mediated chronic condition that imposes a negative impact on patients' quality of life [1]. Accommodating to a chronic illness is always a complex process that is affected by both the patient and the circumstances around him/her [2]. Psoriasis patients may have difficulties adjusting their life to the limitations imposed by their disease, which vary from the need for continuous self-skin care to facing the world with these apparent skin lesions that in turn may limit his/her social activities and interacting with others [3]. Consequently, the patient starts to develop negative feelings like feeling unwanted or invaluable, self-insufficient, shame and embarrassment. The greater the acceptance of illness is, the less the impact of those negative feelings on the patient [4]. The acceptance of illness will improve the adjustment to the disease and decrease the psychosocial implications proposed by the disease [5]. This gives acceptance of illness assessment an importance to be a part of the care routinely presented to psoriasis patients [4]. Literature search revealed no studies that assessed acceptance of illness in Arabic psoriatic patients.

Self-management in chronic dermatologic conditions such as psoriasis is a necessity but patients with psoriasis usually find it difficult [6]. Patients should know about their disease, treatments, how to deal with treatments and their side effects, and how to use topical treatments independently alone at home. Patient education is very important to help patients develop knowledge, ability and confidence in self-management [7]. Patients who are well-educated about

Address for correspondence: Moetaza M. Soliman, Department of Pharmacy Practice, Faculty of Pharmacy, Mansoura University, ElGomhoria St, Mansoura, ElDakahlia, Egypt, phone: 0201142911306, e-mail: moetaza13@yahoo.com Received: 6.05.2020, accepted: 19.05.2020. 
their disease and treatment tend to be more adherent to the treatments and medical advice in general [8]. Adherence to medication results in a greater improvement of the disease and coping skills [9]. Assessment of patients' need for education is a very important preliminary step in patient education and counselling provided by physicians, pharmacists or nurses. Literature search revealed no studies that assessed the need for education to support dermatology self-care in Arabic psoriatic patients.

\section{Aim}

The current study aimed to evaluate acceptance of illness and need for education to support dermatology self-care in Arabic patients with psoriasis.

\section{Material and methods Study design}

An online cross-sectional survey was conducted in order to allow psoriasis patients from different Arabic countries to access the survey. The survey was created in the Arabic language to suit the targeted population. Links to the survey were distributed via different social media sites and were posted on Facebook groups of Arabic psoriatic patients. Inclusion criteria included diagnosis with psoriasis, minimum of 18 years of age, use of topical treatment(s) with or without systemic treatments for psoriasis, and informed consent.

The survey was created using Google Forms and involved two sections. The first section contained information about the study and a consent form to be signed by the patients, patients' demographics and disease characteristics. Information collected included age, sex, nationality, education level and marital status. Disease characteristics included disease duration, disease severity as measured by the self-assessed Simplified Psoriasis Index (saSPI) [10] and quality of life as measured by Dermatology Life Quality Index (DLQI) [11]. The second section contained the outcome measures, namely, the validated Arabic versions of both the Acceptance of IIIness Scale (AIS) and the Person-Centered Dermatology Self-Care Index (PeDeSI).

Ethical approval for this study was obtained from the Institutional Ethical Committee. The study was in accordance with the Helsinki Declaration of 1975, as revised in 2000. No patient identification tools were used.

\section{Outcome measures}

\section{Acceptance of illness scale}

The AIS was developed by Felton et al. to measure the level of illness acceptance in any condition [5]. It consists of eight items and the respondent decides if he/she agrees or disagrees with each item on a five point scale (1 to 5) where 1 represents strong agreement and 5 represents strong dis- agreement. The eight items measure how respondents accommodate with limitations caused by the illness, do what they like the most, think that people around them are uncomfortable with their disease, and feel unwanted, invaluable, self-insufficient, dependent on others or even a burden to family and friends. The score ranges from 8 to 40 where 8 represents extremely low acceptance of the illness and 40 represents extremely high acceptance of illness. The score is interpreted as low (<20), moderate (20-30), or high (>30) level of acceptance of illness.

\section{Person-Centered Dermatology Self-Care Index}

The index was developed by Cowdell et al. [12]. It consists of 10 questions that measure patients' ability, knowledge, and confidence to manage their own long-term skin conditions. The questions test the patient knowledge about his/her disease, use of treatment(s), onset of effectiveness and side effects of treatment(s), quantity and method of application of topical treatment(s), and the level of confidence with dealing with treatment(s) independently at home. The level of independence to perform the task in each question is evaluated by one of four choices; no ability (0), some ability (1), enough ability (2), or full ability (3) generating a score that is ranging from 0 to 30. The score is interpreted as; the patient requires intensive (0-10), some (11-20), limited (21-29), or no (30) education and support to develop knowledge, ability, and confidence.

\section{Statistical analysis}

Descriptive statistics were presented for all included variables. Discrete variables were presented as numbers and percentages while continuous variables were presented as mean \pm SD or median (interquartile range) (IQR) according to data distribution. Outcome measures were presented in total and for different patient groups in relation to age, gender, disease duration, disease severity, quality of life, and level of education. Wilcoxon signed-rank test and Kruskal-Wallis test by ranks were used to compare outcome measures between different patient groups. Multivariate linear regression analyses were performed to identify factors associated with higher AIS and PeDeSI scores. Results of the regression analyses were presented as coefficients and 95\% Confidence Intervals ( $95 \% \mathrm{Cls})$. The correlation between AIS and PeDeSI scores was calculated using Spearman's rank correlation test. The $p$-values $<0.05$ were considered significant. All statistical analyses were carried out using Stata 10.1 software (Stata Corp., College Station, TX, USA).

\section{Results}

\section{Patients' characteristics}

The study involved responses from 209 Arabic psoriatic patients from 12 different Arabic countries. The mean 
\pm SD age was $35.8 \pm 10.0$ years and 144 (68.9\%) patients were males. The median (IQR) disease duration was 12.0 (6.0-20.0) years and the median (IQR) disease severity was 7.5 (3.0-16.0). The median (IQR) quality of life was 10 (5-17). In total, 126 (60.3\%) patients had higher education (university degree) and 143 (68.4\%) were married.
Male patients were older $(p<0.001)$ and less educated $(p=0.02)$ than females (Table 1$)$.

\section{Acceptance of illness}

The patients were moderately accepting their disease (median (IQR) AIS score of 28 (19-35)) with 53 (25.4\%), 75

Table 1. Patients' demographics and disease characteristics

\begin{tabular}{|c|c|c|c|c|c|c|c|}
\hline $\begin{array}{l}\text { Parameter } \\
\text { Age [year], } n(\%):\end{array}$ & \multicolumn{2}{|c|}{$\begin{array}{c}\text { Total } \\
(n=209)\end{array}$} & \multicolumn{2}{|c|}{$\begin{array}{c}\text { Males } \\
(n=144)\end{array}$} & \multicolumn{2}{|c|}{$\begin{array}{c}\text { Females } \\
(n=65)\end{array}$} & $P$-value \\
\hline $18-30$ & 62 & $(29.7)$ & 32 & $(22.2)$ & 30 & $(46.1)$ & \multirow{3}{*}{0.002} \\
\hline $31-40$ & 87 & $(41.6)$ & 64 & $(44.4)$ & 23 & (35.4) & \\
\hline$>40$ & 60 & $(28.7)$ & 48 & $(33.3)$ & 12 & $(18.5)$ & \\
\hline \multicolumn{8}{|l|}{ Disease duration [year], $n(\%)$ : } \\
\hline$<6$ & 49 & $(23.4)$ & 31 & $(21.5)$ & 18 & $(27.7)$ & \multirow[t]{3}{*}{0.55} \\
\hline $6-15$ & 80 & (38.3) & 58 & $(40.3)$ & 22 & (33.8) & \\
\hline$>15$ & 80 & $(38.3)$ & 55 & $(38.2)$ & 25 & $(38.5)$ & \\
\hline \multicolumn{8}{|l|}{ Disease severity (saSPI-s), $n(\%)$ : } \\
\hline Mild $(<10)$ & 120 & $(57.4)$ & 77 & $(53.5)$ & 43 & $(66.2)$ & \multirow[t]{3}{*}{0.11} \\
\hline Moderate (10-20) & 54 & $(25.8)$ & 38 & $(26.4)$ & 16 & $(24.6)$ & \\
\hline Severe $(>20)$ & 35 & $(16.7)$ & 29 & $(20.1)$ & 6 & $(9.2)$ & \\
\hline \multicolumn{8}{|l|}{ Quality of life (DLQI), $n$ (\%): } \\
\hline No effect at all (0-1) & 12 & $(5.7)$ & 10 & $(6.9)$ & 2 & $(3.1)$ & \multirow[t]{5}{*}{0.74} \\
\hline Small effect (2-5) & 44 & $(21.1)$ & 28 & $(19.4)$ & 16 & $(24.6)$ & \\
\hline Moderate effect (6-10) & 59 & $(28.2)$ & 41 & $(28.5)$ & 18 & $(27.7)$ & \\
\hline Very large effect (11-20) & 68 & $(32.5)$ & 46 & $(31.9)$ & 22 & $(33.9)$ & \\
\hline Extremely large effect (21-30) & 26 & $(12.4)$ & 19 & $(13.2)$ & 7 & $(10.8)$ & \\
\hline \multicolumn{8}{|l|}{ Education level, $n(\%)$ : } \\
\hline Below secondary & 30 & $(14.4)$ & 22 & $(15.3)$ & 8 & $(12.3)$ & \multirow[t]{3}{*}{0.02} \\
\hline Secondary & 53 & $(25.4)$ & 44 & $(30.5)$ & 9 & $(13.8)$ & \\
\hline Higher & 126 & $(60.3)$ & 78 & $(54.1)$ & 48 & $(73.9)$ & \\
\hline \multicolumn{8}{|l|}{ Marital status, $n(\%)$ : } \\
\hline Married & 143 & $(68.4)$ & 104 & $(72.2)$ & 39 & $(60.0)$ & \multirow[t]{3}{*}{0.21} \\
\hline Single & 61 & $(29.2)$ & 37 & $(25.7)$ & 24 & $(36.9)$ & \\
\hline Divorced & 5 & $(2.4)$ & 3 & $(2.1)$ & 2 & $(3.1)$ & \\
\hline \multicolumn{8}{|l|}{ Nationality, $n(\%)$ : } \\
\hline Egypt & 37 & $(17.7)$ & 28 & $(19.5)$ & 9 & (13.8) & \multirow[t]{7}{*}{0.54} \\
\hline Iraq & 38 & $(18.2)$ & 29 & $(20.1)$ & 9 & (13.9) & \\
\hline Algeria & 45 & $(21.5)$ & 32 & $(22.2)$ & 13 & $(20.0)$ & \\
\hline Morocco & 20 & $(9.6)$ & 12 & $(8.3)$ & 8 & $(12.3)$ & \\
\hline Jordan & 15 & $(7.2)$ & 8 & $(5.5)$ & 7 & $(10.8)$ & \\
\hline Syria & 20 & $(9.6)$ & 12 & $(8.3)$ & 8 & $(12.3)$ & \\
\hline Other Arabic country & 34 & $(16.3)$ & 23 & $(16.0)$ & 11 & $(16.9)$ & \\
\hline
\end{tabular}

saSPI-s - self-assessed Simplified Psoriasis Index-severity score, DLQI - Dermatology Life Quality Index. 
(35.9\%), and 81 (38.76\%) patients reporting a low, moderate, and high level of acceptance of illness, respectively.

In general, 72 (34.4\%) patients strongly agreed with "being unable to do what they like because of their condition" and 65 (31.1\%) patients strongly agreed with "having problems accommodating with disease limitations" while 108 (51.7\%) patients strongly disagreed with "feeling invaluable because of their disease" and 105 (50.2\%) patients strongly disagreed that "their disease made them a burden to family and friends" (Figure 1).

Acceptance of illness did not differ in relation to age, gender, disease duration, disease severity and level of education (Table 2). However, patients with more impaired quality of life showed lower levels of disease acceptance with median (IQR) of 20.0 (12.0-26.0) and 34.5 (24.0-37.5) for patients with an extremely large effect and those patients with a small effect of psoriasis on quality of life, respectively. The results of the multivariate model predicting the factors associated with a higher AIS score showed that for each unit increase in DLQI score there was -0.6 (95\% Cl: $-0.8,-0.4)$ unit decrease in the AIS score. Higher coefficient values were seen when DLQI increases as shown in different categories of DLQI in Table 3.

\section{Need for education to support dermatology self-care}

The median (IQR) of the PeDeSI score was 15 (11-22) indicating that patients needed some education and support. In total, 135 (64.6\%) patients reported no ability in any of the 10 questions of the PeDeSI while 167 (79.9\%) patients reported full ability in any of the questions.

Table 2. Acceptance of illness and need for education and support in relation to age, gender, disease duration, disease severity, and level of education

\begin{tabular}{|c|c|c|c|c|c|c|c|c|}
\hline \multirow{2}{*}{$\begin{array}{l}\text { Variables } \\
\text { Age [year]: }\end{array}$} & \multicolumn{4}{|c|}{ Acceptance of illness (AIS) } & \multicolumn{4}{|c|}{ Need for education and support (PeDeSI) } \\
\hline & Median & \multicolumn{2}{|c|}{ (IQR) } & $P$-value & Median & \multicolumn{2}{|c|}{ (IQR) } & $P$-value \\
\hline $18-30$ & 25.0 & $(17.0)$ & $(33.0)$ & \multirow[t]{3}{*}{$0.13^{*}$} & 15.0 & (9.0) & $(22.0)$ & \multirow[t]{3}{*}{$0.47^{*}$} \\
\hline $31-40$ & 29.0 & $(17.0)$ & $(36.0)$ & & 15.0 & $(10.0)$ & $(23.0)$ & \\
\hline$>40$ & 29.0 & $(21.5)$ & $(36.0)$ & & 17.0 & $(12.0)$ & $(24.0)$ & \\
\hline \multicolumn{9}{|l|}{ Gender: } \\
\hline Males & 27.5 & $(20.0)$ & $(34.5)$ & \multirow[t]{2}{*}{$0.70^{\star \star}$} & 15.0 & $(11.0)$ & $(21.0)$ & \multirow[t]{2}{*}{$0.38^{\star \star}$} \\
\hline Females & 29.0 & $(17.0)$ & $(35.0)$ & & 17.0 & $(11.0)$ & $(24.0)$ & \\
\hline \multicolumn{9}{|l|}{ Psoriasis duration [year]: } \\
\hline$<6$ & 24.0 & $(18.0)$ & $(34.0)$ & \multirow[t]{3}{*}{$0.31^{*}$} & 15.0 & $(8.0)$ & $(21.0)$ & \multirow[t]{3}{*}{$0.28^{*}$} \\
\hline $6-15$ & 30.0 & $(20.5)$ & $(35.5)$ & & 15.0 & (12.0) & $(22.0)$ & \\
\hline$>15$ & 27.0 & $(18.0)$ & $(35.0)$ & & 17.5 & $(11.0)$ & $(24.0)$ & \\
\hline \multicolumn{9}{|l|}{ Psoriasis severity (saSPI-s): } \\
\hline Mild $(<10)$ & 29.0 & $(20.0)$ & $(36.0)$ & \multirow[t]{3}{*}{$0.13^{*}$} & 17.0 & $(11.0)$ & $(23.0)$ & \multirow[t]{3}{*}{$0.04^{*}$} \\
\hline Moderate (10-20) & 29.0 & $(20.0)$ & $(32.0)$ & & 12.0 & $(10.0)$ & $(19.0)$ & \\
\hline Severe $(>20)$ & 23.0 & $(18.0)$ & $(30.0)$ & & 19.0 & $(12.0)$ & $(25.0)$ & \\
\hline \multicolumn{9}{|l|}{ Quality of life (DLQI): } \\
\hline No effect at all (0-1) & 36.5 & $(34.0)$ & $(39.5)$ & \multirow[t]{5}{*}{$0.001^{*}$} & 27.5 & $(15.0)$ & $(29.5)$ & \multirow[t]{5}{*}{$0.004^{*}$} \\
\hline Small effect (2-5) & 34.5 & $(24.0)$ & $(37.5)$ & & 15.0 & $(10.0)$ & $(23.5)$ & \\
\hline Moderate effect (6-10) & 28.0 & $(21.0)$ & $(34.0)$ & & 17.0 & $(11.0)$ & $(21.0)$ & \\
\hline Very large effect (11-20) & 25.0 & $(16.0)$ & $(31.5)$ & & 16.5 & $(11.5)$ & $(23.5)$ & \\
\hline Extremely large effect (21-30) & 20.0 & $(12.0)$ & $(26.0)$ & & 12.0 & (8.0) & $(17.0)$ & \\
\hline \multicolumn{9}{|l|}{ Education level: } \\
\hline Below secondary & 19.0 & $(12.0)$ & $(36.0)$ & \multirow[t]{3}{*}{$0.16^{\star}$} & 12.5 & $(6.0)$ & $(21.0)$ & \multirow[t]{3}{*}{$0.42^{*}$} \\
\hline Secondary & 25.0 & $(21.0)$ & $(34.0)$ & & 15.0 & $(12.0)$ & $(21.0)$ & \\
\hline Higher & 29.0 & $(20.0)$ & $(35.0)$ & & 17.0 & $(11.0)$ & $(23.0)$ & \\
\hline Total & 28.0 & $(19.0)$ & $(35.0)$ & - & 15.0 & $(11.0)$ & $(22.0)$ & - \\
\hline
\end{tabular}

${ }^{*}$ The Kruskal-Wallis test by ranks, ${ }^{* * W i l c o x o n ~ s i g n e d-r a n k ~ t e s t . ~ I Q R ~-~ i n t e r q u a r t i l e ~ r a n g e, ~ A I S ~-~ a c c e p t a n c e ~ o f ~ I l l n e s s ~ S c a l e, ~ P e D e S I ~-~ P e r s o n-C e n t e r e d ~ D e r m a t o l-~}$ ogy Self-Care Index, saSPI-s - self-assessed Simplified Psoriasis Index-severity score, DLQI - Dermatology Life Quality Index. 


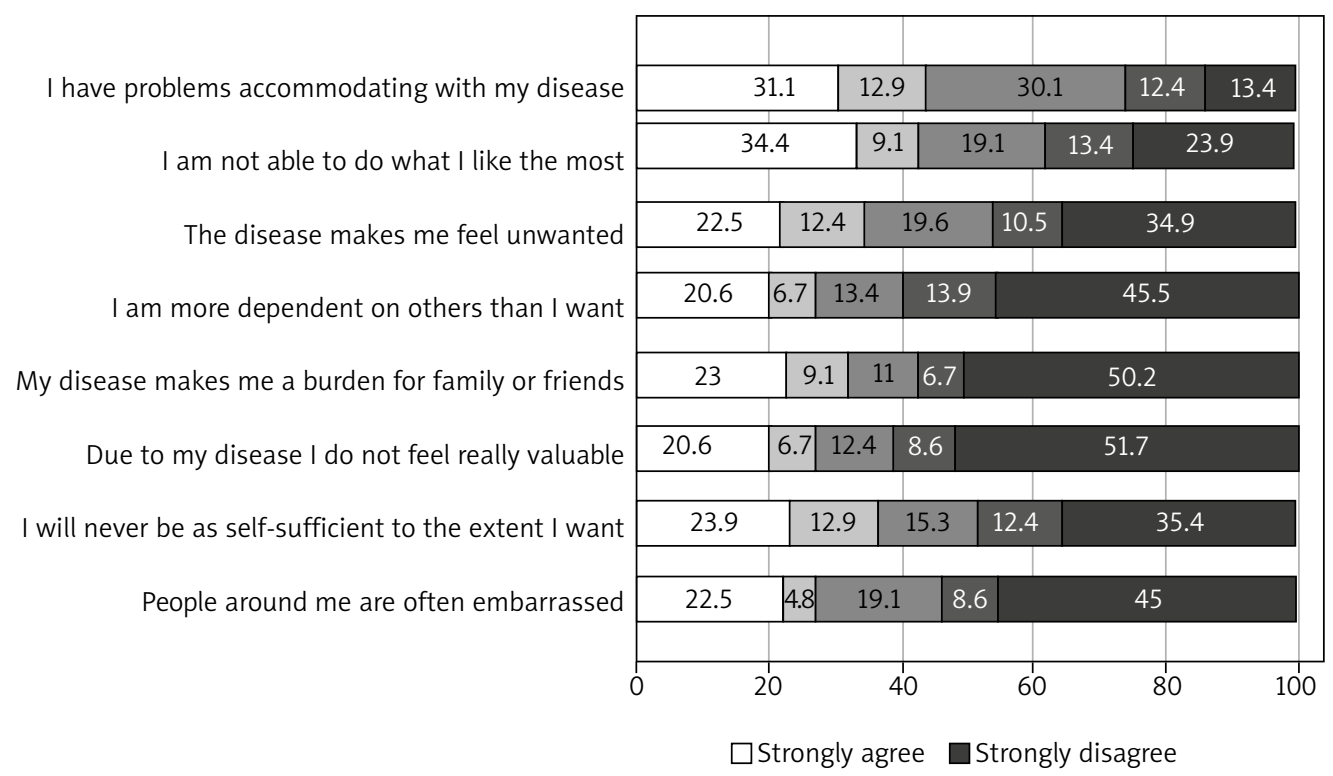

Figure 1. Response to Acceptance of Illness Scale

Table 3. Multivariate linear regression analysis of factors associated with acceptance of illness and need for education and support

\begin{tabular}{|c|c|c|c|c|c|c|}
\hline \multirow[t]{2}{*}{ Characteristics } & \multicolumn{3}{|c|}{ Acceptance of illness (AIS score) } & \multicolumn{3}{|c|}{ Need for education and support (PeDeSI score) } \\
\hline & Coef. & $95 \% \mathrm{Cl}$ & $P$-value & Coef. & $95 \% \mathrm{Cl}$ & $P$-value \\
\hline \multicolumn{7}{|l|}{ Age [year]: } \\
\hline $18-30$ & Ref. & & & & & \\
\hline $31-40$ & 1.7 & $-1.5,4.9$ & 0.29 & 0.8 & $-1.9,3.5$ & 0.56 \\
\hline$>40$ & 3.0 & $-0.6,6.6$ & 0.10 & 0.9 & $-2.1,3.9$ & 0.55 \\
\hline \multicolumn{7}{|l|}{ Gender: } \\
\hline Males & Ref. & & & & & \\
\hline Females & -0.4 & $-3.2,2.4$ & 0.76 & 1.6 & $-0.8,4.0$ & 0.19 \\
\hline \multicolumn{7}{|l|}{ Psoriasis duration [years]: } \\
\hline$<6$ & Ref. & & & & & \\
\hline $6-15$ & 1.6 & $-1.7,5.0$ & 0.33 & 1.6 & $-1.1,4.4$ & 0.25 \\
\hline$>15$ & -0.7 & $-4.2,2.8$ & 0.71 & 2.8 & $-0.2,5.7$ & 0.07 \\
\hline \multicolumn{7}{|l|}{ Psoriasis severity (saSPI-s): } \\
\hline Mild $(<10)$ & Ref. & & & & & \\
\hline Moderate $(10-20)$ & 0.9 & $-2.2,4.0$ & 0.57 & -2.0 & $-4.6,0.6$ & 0.14 \\
\hline Severe $(>20)$ & -0.8 & $-4.7,3.0$ & 0.67 & 3.5 & $0.3,6.8$ & 0.03 \\
\hline \multicolumn{7}{|l|}{ Quality of life (DLQI): } \\
\hline No effect at all (0-1) & Ref. & & & & & \\
\hline Small effect (2-5) & -4.6 & $-10.6,1.4$ & 0.13 & -6.4 & $-11.4,-1.3$ & 0.01 \\
\hline Moderate effect $(6-10)$ & -8.4 & $-14.2,-2.7$ & 0.00 & -6.3 & $-11.1,-1.4$ & 0.01 \\
\hline Very large effect (11-20) & -10.7 & $-16.4,-5.1$ & 0.00 & -5.6 & $-10.4,-0.8$ & 0.02 \\
\hline Extremely large effect (21-30) & -14.0 & $-20.3,-7.6$ & 0.00 & -11.5 & $-16.8,-6.1$ & 0.00 \\
\hline \multicolumn{7}{|l|}{ Education level: } \\
\hline Below secondary & Ref. & & & & & \\
\hline Secondary & 3.1 & $-1.0,7.3$ & 0.14 & 2.7 & $-0.8,6.2$ & 0.13 \\
\hline Higher & 4.2 & $0.5,7.9$ & 0.02 & 2.5 & $-0.6,5.6$ & 0.11 \\
\hline
\end{tabular}

Coef. - coefficients, Ref. - reference, Cl - confidence intervals, AIS - Acceptance of Illness Scale, PeDeSI - Person-Centered Dermatology Self-Care Index, saSPI-s - self-assessed Simplified Psoriasis Index-severity score, DLQI - Dermatology Life Quality Index. 


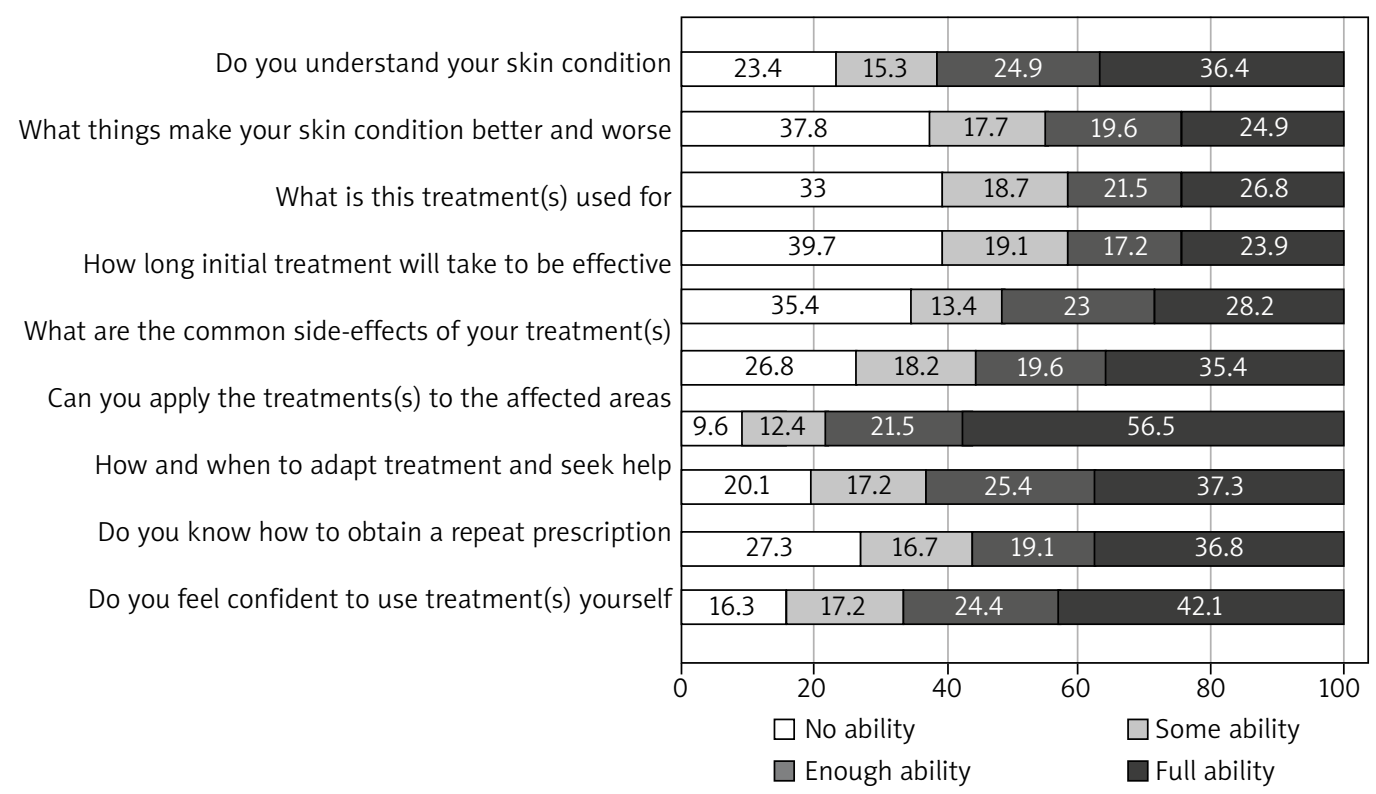

Figure 2. Response distribution to the Person-Centered Dermatology Self-Care Index

Generally, 83 (39.7\%) patients did not know the onset of effectiveness of the initial treatment, 79 (37.8\%) patients did not know things that improve or worsen their psoriasis, and 74 (35.4\%) patients did not know the common side effects of their treatment(s) (Figure 2). Ability to apply topical treatment(s) to the affected areas showed the highest percent of full ability (56.5\%) among this group of patients while feeling comfortable using the treatment(s) at home showed the lowest percent of full ability (23.9\%).

In total, 49 (23.4\%), 86 (41.2\%), and 62 (29.7\%) patients required intensive, some, and limited education and support to develop knowledge, confidence and ability, respectively. Only 12 (5.7\%) patients had enough knowledge, ability and confidence to manage on their own.

Need for education and support did not differ in relation to age, gender, disease duration, and level of education. However, patients with moderate psoriasis reported a higher need for education and support ( $p=$ 0.04) compared to those with mild disease. Patients with severe disease reported a lower need for education and support (Table 2). Patients with more impaired quality of life showed a higher need for education and support $(p=0.004)$. The results of the multivariate analysis predicting the factors associated with a higher PeDeSI score showed that for each unit increase in disease severity (SaSPI) there was $3.5(95 \% \mathrm{Cl}$ : 0.3, 6.8) increase in the PeDeSI score. The results of the multivariate analysis also showed that for each unit increase in DLQI there was $-0.3(95 \% \mathrm{Cl}$ : $-0.4,-0.1)$ decrease in the PeDeSI score. Higher coefficient values were seen when DLQI increases as shown in different categories of DLQI in Table 3.
A moderate correlation was seen between acceptance of illness and the need for education and support (Spearman's rho $=0.33, p=0.00$ ) (Figure 3).

\section{Discussion}

In this study two different patient-reported outcomes were assessed in Arabic psoriatic patients, namely, the acceptance of illness and the need for education to support dermatology self-care.

The level of psoriasis acceptance within the 209 participating patients was moderate with a median (IQR) AIS score of 28 (19-35). Due to the great diversity of different chronic diseases, it is quite hard to compare acceptance of illness across different conditions. However, the cur-

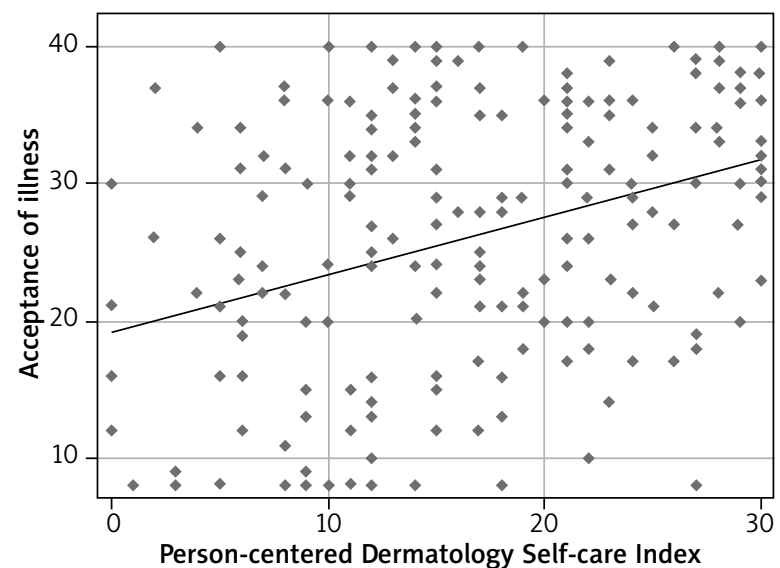

Figure 3. Correlation between acceptance of illness and need for education and support 
rently reported acceptance of psoriasis was comparable to that of the most common chronic conditions such as diabetes (mean \pm SD of $26.95 \pm 8.50$ ) [13], chronic pulmonary diseases (median (IQR) of 27.0 (19.8-32.0)) [14], and cancer (mean \pm SD of $26.63 \pm 6.04$ ) [15]. The currently presented level of acceptance of psoriasis in this study was also comparable to other populations with psoriasis, as reported recently for 366 psoriatic patients from Poland with a mean \pm SD of $24.02 \pm 7.56$ [16]. The current results showed that the acceptance of illness did not differ by gender, age, disease duration, and disease severity. Similar findings were presented for 100 psoriatic patients in 2007 [17].

Arabic psoriatic patients who participated in this study reported some need for education to support dermatology self-care with median (IQR) of the PeDeSI score being 15 (11-22). Similar results were reported for 47 psoriatic patients from the United Kingdom (mean \pm SD of $17.78 \pm 4.49)$ [18].

The results showed that patients with more impaired quality of life showed lower levels of disease acceptance and a higher need for education and support. The insufficient knowledge about the disease and the denial of the disease may be contributing factors to worse quality of life. Previous studies reported a strong correlation between the need for education as measured by PeDeSI and quality of life (as measured by DLQI) in German psoriatic patients [19]. An association between acceptance of illness and quality of life was also seen in other illnesses such as chronic pulmonary diseases [14].

Unexpectedly, the results of the multivariate analysis showed that patients with severe disease (saSPI > 20) required lower levels of education and support. This may be explained by already received proper education and support. In other words, physicians, pharmacists and nurses actually recognized the need for education and counselling for this group of patients with severe disease but it seems that less attention was given to patients with mild or moderate disease.

Interestingly, there was a moderate correlation between AIS and PeDeSI scores which may be explained by the fact that the more the patients are educated about their disease management, the more the patients will accept the disease.

To our knowledge, this is the first available study to assess acceptance of illness and the need for education and support in Arabic population with psoriasis or with any chronic dermatologic condition. It is obvious that assessing acceptance of illness is the first step to avoid any consequent impairment in quality of life. Besides, assessing the need for education and support is a very important preliminary step for proper patient education and counselling. The research was based on using the Arabic language AIS and PeDeSI questionnaires previously translated and validated by the author (under review). The author believes that the availability of such versions of the questionnaires will help to study the acceptance of illness and the need for education and support in other dermatologic conditions within the Arabic population in the future.

The online study design allowed for survey completion at the time suitable for the patients and it allowed access to psoriasis patients from different Arabic countries. Previous studies used the online approach to collect patient reported outcomes in psoriasis [20]. The crosssectional design was fast, cheap, and easy to conduct.

The limitations of the current study may arise from the small sample size; however, the patients were from 12 different countries which may represent the Arabic population where every country might have its own health care policy. Another limitation might be the fact that the participant population did not include elderly patients; out of the 209 participants only 3 (1.4\%) patients were above 60 years of age. This may be explained by the fact that such elderly patients might not be familiar with the idea of completing an online survey. However, 60 (28.7\%) patients were above 40 years of age and 14 (6.7\%) were above 50 years.

\section{Conclusions}

Arabic psoriatic patients who participated in this survey showed moderate acceptance of illness and required some education to support dermatology self-care. Psychotherapy may be of benefit especially for those with low levels of illness acceptance. Patient education and counselling should receive greater attention with Arabic psoriatic patients especially those with more impaired quality of life.

\section{Acknowledgments}

The author would like to thank all study participants for completing the survey.

\section{Conflict of interest}

The author declares no conflict of interest.

\section{References}

1. Krueger GG, Feldman SR, Camisa C, et al. Two considerations for patients with psoriasis and their clinicians: what defines mild, moderate, and severe psoriasis? What constitutes a clinically significant improvement when treating psoriasis? J Am Acad Dermatol 2000; 43: 281-5.

2. Felton BJ, Revenson TA. Coping with chronic illness: a study of illness controllability and the influence of coping strategies on psychological adjustment. J Consult Clin Psychol 1984; 52: 343-53.

3. Fortune DG, Richards HL, Griffiths CEM. Psychologic factors in psoriasis: consequences, mechanisms, and interventions. Dermatol Clin 2005; 23: 681-94. 
4. Mazurek J, Lurbiecki J. Acceptance of illness scale and its clinical impact. Pol Merkur Lekarski 2014; 36: 106-8.

5. Felton BJ, Revenson TA, Hinrichsen GA. Stress and coping in the explanation of psychological adjustment among chronically ill adults. Soc Sci Med 1984; 18: 889-98.

6. Ersser SJ, Cowdell FC, Latter SM, Healy E. Self-management experiences in adults with mild-moderate psoriasis: an exploratory study and implications for improved support. Br J Dermatol 2010; 163: 1044-9.

7. Rasmussen GS, Maindal HT, Lomborg K. Self-management in daily life with psoriasis: an integrative review of patient needs for structured education. Nurs Res Pract 2012; 2012: 890860.

8. Wang W, Qiu Y, Zhao F, Zhang F. Poor medication adherence in patients with psoriasis and a successful intervention. J Dermatolog Treat 2019; 30: 525-8.

9. Carroll CL, Feldman SR, Camacho FT, Balkrishnan R. Better medication adherence results in greater improvement in severity of psoriasis. Br J Dermatol 2004; 151: 895-7.

10. Chularojanamontri L, Griffiths CEM, Chalmers RJG. The Simplified Psoriasis Index (SPI): a practical tool for assessing psoriasis. J Invest Dermatol 2013; 133: 1956-62.

11. Finlay AY, Khan GK. Dermatology Life Quality Index (DLQI): a simple practical measure for routine clinical use. Clin Exp Dermatol 1994; 19: 210-6.

12. Cowdell F, Ersser SJ, Gradwell C, Thomas PW. The PersonCentered Dermatology Self-Care Index: a tool to measure education and support needs of patients with long-term skin conditions. Arch Dermatol 2012; 148: 1251-5.

13. Rogon I, Kasprzak Z, Szcześniak Ł. Perceived quality of life and acceptance of illness in people with type 2 diabetes mellitus. Menopause Rev 2017; 16: 79-85.

14. Chabowski M, Juzwiszyn J, Bolanowska Z, et al. B. Acceptance of illness associates with better quality of life in patients with nonmalignant pulmonary diseases. Adv Exp Med Biol 2019; 1176: 19-24.

15. Pasek M, Dębska G, Wojtyna E. Perceived social support and the sense of coherence in patient-caregiver dyad versus acceptance of illness in cancer patients. J Clin Nurs 2017; 26: 4985-93.

16. Kowalewska B, Cybulski M, Jankowiak B, Krajewska-Kułak E. Acceptance of illness, satisfaction with life, sense of stigmatization, and quality of life among people with psoriasis: a cross-sectional study. Dermatol Ther 2020; 10: 413-30.

17. Zalewska A, Miniszewska J, Chodkiewicz J, Narbutt J. Acceptance of chronic illness in psoriasis vulgaris patients. J Eur Acad Dermatol Venereol 2007; 21: 235-42.

18. Tucker R, Stewart D. The role of community pharmacists in supporting self-management in patients with psoriasis. Int J Pharm Pract 2017; 25: 140-6.

19. Kottner J, Ludwig O, Bode T, et al. Person-Centred Dermatology Self-care Index: a translation and validation study. J Wound Care 2019; 28: 566-75.

20. Henry AL, Kyle SD, Chisholm A, et al. A cross-sectional survey of the nature and correlates of sleep disturbance in people with psoriasis. Br J Dermatol 2017; 177: 1052-9. 